\title{
Oral complementary medicine and alternative practitioner use varies across chronic conditions and attitudes to risk
}

This article was published in the following Dove Press journal:

Clinical Epidemiology

4 November 2010

Number of times this article has been viewed

\author{
Robert J Adams' \\ Sarah L Appleton' \\ Antonia Cole ${ }^{2}$ \\ Tiffany K Gill ${ }^{3}$ \\ Anne W Taylor ${ }^{3}$ \\ Catherine L Hill' \\ 'The Health Observatory, \\ ${ }^{2}$ Rheumatology Unit, ${ }^{3}$ Population \\ Research and Outcomes Unit, SA \\ Health, The University of Adelaide \\ Discipline of Medicine, Queen \\ Elizabeth Hospital, Woodville, \\ Australia
}

Objectives: To determine whether chronic conditions and patient factors, such as risk perception and decision-making preferences, are associated with complementary medicine and alternative practitioner use in a representative longitudinal population cohort.

Participants and setting: Analysis of data from Stage 2 of the North West Adelaide Health Study of 3161 adults who attended a study clinic visit in 2004-2006. The main outcome measures were the medications brought by participants to the study clinic visit, chronic health conditions, attitudes to risk, levels of satisfaction with conventional medicine, and preferred decision-making style.

Results: At least one oral complementary medicine was used by $27.9 \%$ of participants, and $7.3 \%$ were visiting alternative practitioners (naturopath, osteopath). Oral complementary medicine use was significantly associated with arthritis, osteoporosis, and mental health conditions, but not with other chronic conditions. Any pattern of complementary medicine use was generally significantly associated with female gender, age at least 45 years, patient-driven decision-making preferences (odds ratio [OR] 1.38, 95\% confidence interval [CI]: 1.08-1.77), and frequent general practitioner visits ( $>$ five per year; OR 3.62, 95\% CI: 2.13-6.17). Alternative practitioner visitors were younger, with higher levels of education (diploma/trade [OR 1.88, 95\% CI: 1.28-2.76], bachelor's degree [OR 1.77, 95\% CI: 1.11-2.82], income $>\$ 80,000$ (OR 2.28, 95\% CI: 1.26-4.11), female gender (OR 3.15, 95\% CI: 2.19-4.52), joint pain not diagnosed as arthritis (OR 1.68, 95\% CI: 1.17-2.41), moderate to severe depressive symptoms (OR 2.15, 95\% CI: 1.04-4.46), and risk-taking behavior (3.26, 1.80-5.92), or low-to-moderate risk aversion (OR 2.08, 95\% CI: 1.26-4.11).

Conclusion: Although there is widespread use of complementary medicines in the Australian community, there are differing patterns of use between those using oral complementary medicines and those using alternative practitioners.

Keywords: complementary medicine, chronic disease, risk attitudes, population study

\section{Introduction}

Population studies indicate that the use of complementary medicine has become increasingly popular in Australia and in other Western countries. There appears to be no consensus on the definition of "complementary medicine" therapy. Complementary medicine covers a range of oral supplements, herbal medicines, vitamins, and minerals. Some studies have also included chiropractic therapies, osteopathy, nutritional therapies, exercise-based therapies, aromatherapy, massage, and acupuncture. The National Institute for Complementary Medicine in Australia has adopted, with revisions, the four domains of complementary medicine articulated by the US National Center for Complementary and Alternative Medicine (www.nicm.edu.au). These four domains are mind-body medicine, biologically based practices, manipulative and body-based
Correspondence: Robert Adams

The University of Adelaide Discipline of Medicine, Queen Elizabeth Hospital, 28 Woodville Road, Woodville, SA 50II, Australia Email robert.adams@adelaide.edu.au 
practices, and energy systems. In addition, whole medical systems are included which can cut across domains. These include homeopathy, naturopathy, and traditional Chinese medicine. This study focuses on biologically based practices (such as herbs, foods, and vitamins), including what the Australian Therapeutic Goods Administration defines and regulates as complementary medicines, and whole systems (such as naturopathy).

Despite the popularity of complementary medicine, ${ }^{1-3}$ previous Australian studies ${ }^{1,4-6}$ have not assessed complementary medicine use in relation to chronic conditions and risk factors, or identified preferences or risk perceptions of complementary medicine users. International surveys often find that oral complementary medicine use is more prevalent among younger women from higher socioeconomic backgrounds. ${ }^{2,3}$ However, one US study suggested that risk attitude is as strong a predictor of visits to alternative practitioners as are sociodemographic factors. ${ }^{7}$ This study also showed that attitudes to risk differed between people who used oral complementary medicine and those who attended complementary practitioners such as naturopaths. The latter group perceive themselves as risk-takers, compared with self-administering complementary medicine users who rated themselves not differently from the general population, ${ }^{7}$ but we are not aware that this research has been replicated. The relationship between dissatisfaction or distrust with orthodox medicine and complementary medicine use also remains unclear. ${ }^{8-10}$ An understanding of the relationship between complementary medicine use and preferences for autonomy in decision-making about care is also limited by a lack of representative data, but studies in selected populations suggest no relationship. ${ }^{8,11}$

The aim of this population-based study was to assess the prevalence of oral complementary medicine use and the demographics of complementary medicine users; the associations of oral complementary medicine use and complementary practitioner visits with lifestyle risk factors and chronic medical conditions; and whether complementary medicine use is related to attitude to risk and decision-making. We also assessed the relationship between oral complementary medicine use and complementary practitioner visits and attitudes towards risk, participatory decision-making style, and satisfaction with conventional medicine, because this has rarely been described previously in a large representative population sample.

\section{Methods}

\section{Sample population and study method}

Participants of the North West Adelaide Health Study (NWAHS) were recruited from households randomly selected from the electronic telephone directory in 2000-2002. At follow-up of the NWAHS cohort in 2004-2005 (response rate $81.0 \%$ ), clinical assessment and medication data were available for 3161 individuals. The methods of the NWAHS ${ }^{12}$ and the validity of these methods of selection to achieve an unbiased sample ${ }^{13}$ have been described previously. In particular, there were no major differences between study participants and the comparison population in terms of health indicators or lifestyle behaviors. ${ }^{14}$ The study was approved by the Institutional Ethics Committee of the North West Adelaide Health Service, and all subjects gave written informed consent.

Respondents completed telephone and written questionnaires, and underwent clinical assessment including spirometry, measurement of blood pressure, weight, height, and fasting blood tests for plasma glucose and lipids. Questionnaires collected information on health behaviors (smoking, recreational physical activity, and alcohol use), doctor-diagnosed conditions, including rheumatoid arthritis, osteoarthritis, osteoporosis, diabetes, chronic obstructive pulmonary disease, asthma, cardiovascular disease (myocardial infarction, angina, stroke) and mental health conditions, symptoms of joint pain (in foot, knee, hip, hand, and/or shoulder), depression, health service utilization (visits in the last 12 months to primary care providers, psychologists, chiropractors, and other therapists, including osteopaths and naturopaths), and demographics.

Current oral complementary medicine use was identified by asking participants to bring all medications, including prescription medications that they were currently using, to the clinic visit (Table 1). Information on duration of use was not obtained. Vitamin D, calcium, and iron supplements were not considered to be oral complementary medicines when

Table I Prevalence of oral complementary medicine use by type

\begin{tabular}{|c|c|c|c|}
\hline \multicolumn{4}{|c|}{ Complementary medicine type \% (n) } \\
\hline Multivitamin & I3.3 (420) & Black cohosh & $0.6(19)$ \\
\hline Fish oil & $6.0(188)$ & Magnesium & $0.6(20)$ \\
\hline $\begin{array}{l}\text { Glucosamine/shark } \\
\text { cartilage }\end{array}$ & 5.7 (179) & Probiotics & $0.5(15)$ \\
\hline Vitamin C & $3.0(95)$ & Saw Palmetto & $0.4(13)$ \\
\hline Other herbal & $2.8(89)$ & St. John's wort & $0.4(\mid 2)$ \\
\hline Vitamin B & $2.7(86)$ & Amino acid & $0.4(12)$ \\
\hline Vitamin $\mathrm{E}$ & $2.0(62)$ & Flaxseed oil & $0.3(8)$ \\
\hline Ginkgo biloba & $1.6(50)$ & Coenzyme Q10 & $0.3(\mathrm{II})$ \\
\hline Evening primrose oil & $1.5(48)$ & Celery & $0.2(6)$ \\
\hline Garlic & $1.4(44)$ & Echinacea & $0.2(7)$ \\
\hline Zinc & I.I (36) & Ginseng & $0.2(5)$ \\
\hline Mineral & $0.8(26)$ & Emu oil & $0.1(3)$ \\
\hline Cod liver oil & $0.7(22)$ & & \\
\hline
\end{tabular}


they had been prescribed by a medical practitioner for an underlying medical condition.

\section{Chronic conditions}

Undiagnosed joint pain was defined as pain in at least one site (foot, knee, hip, hand, shoulder) that had not been previously classified by a doctor as osteoarthritis, rheumatoid arthritis, or other arthritis. Diabetes, asthma, and chronic obstructive pulmonary disease were defined by clinic measurements or report of doctor-diagnosis, as has been described previously. ${ }^{12}$ Asthma was defined as current self-reported physician-diagnosed asthma or demonstration of a significant bronchodilator response of at least $12 \%$ of baseline forced expiratory volume in one second $\left(\mathrm{FEV}_{1}\right)$ in the absence of a doctor-diagnosis of asthma. ${ }^{15,16}$ Participants with persistent airways obstruction, ie, postbronchodilator $\mathrm{FEV}_{1}$ /forced vital capacity (FVC) ratio less than $0.70^{17}$ were also identified as having chronic obstructive pulmonary disease. Diabetes was defined as fasting blood glucose $\geq 7.0 \mathrm{mmol} / \mathrm{L}$, self-reported physician diagnosis of diabetes, or treatment for diabetes. Depression was assessed with the Center for Epidemiologic Studies Depression Scale (CES-D), a 20-item questionnaire which covers the major components of depressive symptomatology. ${ }^{18}$ CES-D scores range from 0 to 60 , with scores 16-26 considered indicative of mild depression, and scores of $\geq 27$ indicative of major depression. ${ }^{19,20}$

\section{Lifestyle variables}

Body mass index (weight/height squared, in $\mathrm{kg} / \mathrm{m}^{2}$ ) was categorized according to international criteria, ie, underweight/ normal $\leq 24.9$, overweight $25.0-29.9$, and obesity: $\geq 30.0 .{ }^{21}$ Recreational physical activity was calculated as the number of times activity was undertaken by average time per session by (self-perceived) intensity ${ }^{22}$ and categorized as sedentary, low, moderate, and high exercise. Risk level of alcohol use (intermediate- to very high-risk) was classified as at least an average daily intake of four drinks (or 9-12 drinks in any day) in females and an average daily intake of 5-8 drinks (or occasional excess) in males. ${ }^{23}$

\section{Risk aversion, decision-making preferences, and satisfaction with care}

An individual's level of risk aversion was assessed $(\mathrm{n}=2342)$ by using questions based on data obtained from a National Patient Safety Foundation survey in America. ${ }^{24}$ Risk aversion was assessed using the following questions: "On a scale of 1 to 7 , with $7=$ very risky and $1=$ not risky at all, how risky do you think the following behaviors are: a. Not testing smoke detectors regularly if they are in your home?

b. Leaving appliances plugged in while you are away for an extended period of time?

c. Smoking tobacco or cigarettes?

d. Using foodstuffs after use-by date?

e. Driving a car after consuming alcohol?

f. Not carrying medical identification when you have a medical condition such as allergies, diabetes, or epilepsy?"

The scoring system was modified (to take into account missing data on some items) so that the average of the responses to these six questions was used; $6.66-7$ was coded as highly risk-averse, 5-6.65 was coded as moderately riskaverse, and $<5$ were considered to be risk-takers. ${ }^{25}$

Patient satisfaction with conventional medicine was assessed by the following question: "Thinking about your most recent experience with a doctor or hospital, how satisfied were you with the health care you received?" (very satisfied, somewhat satisfied, somewhat dissatisfied, very dissatisfied). Patient preferred decision-making was assessed by the response to: "In what way do you prefer to make decisions regarding your health care or medical treatments?" ("I prefer the final decision to be made:

By me (on basis of my own knowledge of risks/benefits or by strongly considering the doctor's opinion)

On an equal basis with the doctor

By the doctor (on the basis of their knowledge of risks/ benefits or with my opinion considered)".

\section{Statistical analysis}

Data were weighted to census data by region, age group, gender, and probability of selection in the household, to provide population-representative estimates. Data were analyzed using SPSS (Version 15.0, SPSS Inc, Chicago, IL). Chi-square tests determined differences in proportions of those using complementary medicines in relation to sociodemographic, chronic disease, and chronic disease risk factors. All variables (chronic conditions, risk factors, health service use, individual factors such as risk aversion) were then entered into multivariable logistic regression analyses to develop separate models for the factors associated with oral complementary medicine use and alternative practitioner visits, adjusted for covariates including age, gender, smoking status, body mass index, and socioeconomic status (education, income, employment status). Variables were progressively removed from models and the effect on associations and the model-fit were examined. Results are expressed as odds ratios (OR) with $95 \%$ confidence intervals (CI). 


\section{Results}

The prevalence of oral complementary medicine use by type is listed in Table 1. Overall 883 (27.9\%) of study participants were currently taking one or more complementary medicines. The prevalence of subjects taking $1-2,3-4$, and $\geq 5$ complementary medicines was $22.4 \%(n=709), 4.5 \%(n=143)$, and $1.0 \%(\mathrm{n}=31)$, respectively. Approximately half of all oral complementary medicines were reported to be taken for general health and well-being and one quarter were used for muscle, bone, and joint health (Table 2). At univariate level, oral complementary medicine use was associated with female gender, older age, and not being in the paid workforce, but not with other socioeconomic factors (education or household income). Only a limited range of chronic medical conditions were associated with increased oral complementary medicine use, including diagnosed arthritis (as well as symptoms of joint pain/stiffness), osteoporosis, chronic obstructive pulmonary disease, and mental health conditions (Table 3). Complementary practitioner visits (naturopaths, osteopaths) were reported by $7.3 \%(n=230)$, and were associated with differing sociodemographics compared with oral complementary medicine users, including younger age, higher levels of education, and being in the paid workforce (Table 3). These differences are reflected in the significantly increased visits to complementary practitioners in those without risk factors or chronic disease. Table 4 shows that health care use in the previous 12 months was significantly associated with oral complementary medicine use, including visits to primary care providers, chiropractors, or alternative therapists.

In multivariable analyses, multiple oral complementary medicine use showed specific associations with social/ biomedical factors compared with those using only one

Table 2 Reasons for oral complementary medicine use identified by participants

\begin{tabular}{lll}
\hline Reason & $\%$ & $\mathbf{n}$ \\
\hline General health and well-being & 53.3 & 862 \\
Muscles, bones, and joints & 24.0 & 384 \\
Nerves/stress/brain health & 3.9 & 62 \\
Premenstrual symptoms/menopause & 3.6 & 57 \\
Lung/sinuses & 3.4 & 55 \\
Skin & 3.3 & 53 \\
Circulation/cardiovascular disease & 3.1 & 49 \\
Gastrointestinal system and liver & 0.7 & 11 \\
Eye health & 0.6 & 10 \\
Prostate & 0.5 & 8 \\
Bladder/kidneys & 0.2 & 3 \\
Other & 3.4 & 54 \\
Total & 100.0 & 1608 \\
\hline
\end{tabular}

complementary medicine, including normal body weight, higher income levels, with visits to psychologists and complementary practitioners and with patient driven/shared decision-making preferences (Table 5). In contrast, use of only one complementary medicine was significantly associated with higher education levels and specific morbidities (diagnosed arthritis, depressive symptoms).

Complementary medicine use was significantly associated with a patient-driven preference for decision-making in relation to their medical treatment, but not with attitudes towards risk-taking or patient satisfaction. In contrast, the visits to complementary practitioners were significantly associated with attitudes towards risk-taking (Table 4). People attending complementary practitioners were significantly more likely $(P<0.05)$ to be classified as risk-takers (36\%) than either oral complementary medicine users only $(14 \%)$ or nonusers $(15 \%)$. There were no differences in the frequency of general practitioner visits between those who also attended complementary practitioners and those who did not. In regression analyses, complementary practitioner visitors were significantly associated with higher levels of education (diploma/trade [OR 1.88, 95\% CI: 1.28-2.76], bachelor's degree [OR 1.77, 95\% CI: 1.11-2.82]), annual household income of at least \$80,000 (OR 2.28, 95\% CI: 2.28 , 1.26-4.11), female gender (OR 3.15, 95\% CI: 2.19-4.52), normal weight (OR 2.38, 95\% CI: 1.51-3.76) or overweight (OR 2.04, 95\% CI: 1.30-3.21), joint pain not diagnosed as arthritis (OR 1.68, 95\% CI: 1.17-2.41), moderate to severe depressive symptoms (OR 2.15, 95\% CI: 1.04-4.46), and with risk-taking behavior (OR 3.26, 95\% CI: 1.80-5.92) or mildmoderate risk aversion (OR 2.08, 95\% CI: 1.26-4.11).

People with mental health conditions were significantly more likely to report use of St. John's wort and vitamin supplements (Table 6). Those with diagnosed arthritis were significantly more likely to report use of fish oil and glucosamine or shark cartilage, compared with either people with undiagnosed joint pain or no joint pain. People visiting complementary practitioners (naturopath or osteopath) were significantly more likely to be using vitamin supplements, herbal preparations, probiotics, and black cohosh, as well as fish oil and glucosamine/shark cartilage.

\section{Discussion}

Our results confirm that oral complementary medicine use is common in the Australian community. We identified subjects currently taking oral complementary medicines, and this is likely to have resulted in the lower prevalence rate compared with previous population studies recording complementary medicine use in the previous 12 months. ${ }^{4}$ 
Table 3 Prevalence of oral complementary medicine and alternative practitioner use in relation to demographic factors, chronic disease, and chronic disease risk factors

\begin{tabular}{|c|c|c|c|c|c|}
\hline Factors & & $\begin{array}{l}\text { Oral CM } \\
\%(n)\end{array}$ & $P$ & $\begin{array}{l}\text { Alternative } \\
\text { practitioner } \\
\%(n)\end{array}$ & $P$ \\
\hline \multicolumn{6}{|l|}{ Demographics } \\
\hline \multirow[t]{2}{*}{ Sex } & Male & $21.4(330)$ & $<0.01$ & $4.4(69)$ & $<0.01$ \\
\hline & Female & $34.2(553)$ & & $10.0(161)$ & \\
\hline \multirow[t]{3}{*}{ Age, years } & $<45$ & $23.7(363)$ & $<0.01$ & $8.8(137)$ & $<0.01$ \\
\hline & $45-64$ & $31.7(3 \mid 5)$ & & $7.4(74)$ & \\
\hline & $65+$ & $32.3(205)$ & & $3.1(19)$ & \\
\hline \multirow[t]{3}{*}{ Education } & Secondary school & $26.3(384)$ & 0.15 & $4.4(65)$ & $<0.01$ \\
\hline & diploma, trade qualification & $29.5(340)$ & & $8.3(96)$ & \\
\hline & university degree & $29.2(159)$ & & $12.5(68)$ & \\
\hline \multirow[t]{4}{*}{ Annual household income } & $<\$ 20,000$ & $27.8(166)$ & 0.95 & $4.1(24)$ & $<0.01$ \\
\hline & $\$ 20,00 \mathrm{I}-50,000$ & $27.8(288)$ & & $5.5(58)$ & \\
\hline & $\$ 50,00 \mathrm{I}-80,000$ & $28.9(239)$ & & $8.0(66)$ & \\
\hline & $\geq \$ 80,00 \mathrm{I}$ & $27.2(15 \mid)$ & & I3.I (73) & \\
\hline \multirow[t]{2}{*}{ Employed } & No & $30.7(319)$ & 0.01 & $4.2(43)$ & $<0.01$ \\
\hline & Yes & $26.4(55 I)$ & & $8.8(187)$ & \\
\hline \multicolumn{6}{|l|}{ Chronic disease } \\
\hline \multirow{3}{*}{ Diabetes } & No & $27.9(8 \mid 4)$ & 0.88 & $7.5(220)$ & 0.11 \\
\hline & Undiagnosed ${ }^{\ddagger}$ & $25.0(6)$ & & $3.6(7)$ & \\
\hline & Diagnosed $^{\dagger}$ & $29.1(58)$ & & $8.3(2)$ & \\
\hline \multirow[t]{3}{*}{ Asthma } & No & $27.7(722)$ & 0.56 & $7.0(182)$ & 0.18 \\
\hline & Undiagnosed $¥$ & $26.8(34)$ & & $7.9(10)$ & \\
\hline & Diagnosed $^{\dagger}$ & $30.1(122)$ & & $9.5(38)$ & \\
\hline \multirow[t]{2}{*}{ Arthritis } & No & $25.7(630)$ & $<0.01$ & $7.5(188)$ & 0.09 \\
\hline & Yes & $36.1(234)$ & & $5.6(37)$ & \\
\hline \multirow[t]{2}{*}{ Joint pain/stiffness ${ }^{*}$} & No & $22.9(300)$ & $<0.01$ & $6.3(109)$ & $<0.01$ \\
\hline & Yes & $32.1(531)$ & & $8.5(121)$ & \\
\hline \multirow[t]{2}{*}{ Osteoporosis ${ }^{\dagger}$} & No & $27.4(824)$ & 0.007 & $7.4(224)$ & 0.23 \\
\hline & Yes & $38.9(44)$ & & $4.4(5)$ & \\
\hline \multirow[t]{2}{*}{ Mental health condition ${ }^{\dagger}$} & No & $26.8(708)$ & $<0.01$ & $6.5(173)$ & $<0.01$ \\
\hline & Yes & $33.8(161)$ & & $11.6(56)$ & \\
\hline \multirow[t]{3}{*}{ Depressive symptoms (CES-D) } & None & $26.5(725)$ & $<0.01$ & $6.9(192)$ & 0.11 \\
\hline & Mild & $37.3(100)$ & & $9.3(25)$ & \\
\hline & Moderate/severe & $40.0(44)$ & & $10.9(12)$ & \\
\hline \multirow[t]{2}{*}{$\mathrm{CVD}^{\dagger}$} & No & $27.9(8 \mid 4)$ & 0.62 & $7.5(222)$ & 0.03 \\
\hline & Yes & $26.3(54)$ & & $3.4(7)$ & \\
\hline \multirow[t]{2}{*}{ COPD $¥$} & No & $28.1(837)$ & 0.03 & $7.3(2 \mid 8)$ & 0.15 \\
\hline & Yes & $19.7(24)$ & & $4.1(6)$ & \\
\hline \multicolumn{6}{|l|}{ Risk factors } \\
\hline \multirow[t]{3}{*}{ Smoking status } & Never & $28.7(4 \mid 3)$ & $<0.01$ & $8.4(120)$ & 0.07 \\
\hline & Former & $30.6(330)$ & & $6.8(74)$ & \\
\hline & Current & $21.8(136)$ & & $5.6(35)$ & \\
\hline \multirow[t]{3}{*}{$\mathrm{BMI}^{\ddagger}$} & Normal & $31.8(334)$ & $<0.01$ & $9.2(96)$ & $<0.01$ \\
\hline & Overweight & 25.3 (299) & & $7.4(88)$ & \\
\hline & Obese & $27.0(251)$ & & $4.8(45)$ & \\
\hline High blood pressure ${ }^{\ddagger}$ & No & $27.8(645)$ & 0.48 & $8.2(191)$ & $<0.01$ \\
\hline & Yes & $28.7(233)$ & & $4.5(37)$ & \\
\hline High total cholesterol ${ }^{\ddagger}$ & No & $28.0(521)$ & 0.88 & $7.9(148)$ & 0.10 \\
\hline & Yes & $28.2(362)$ & & $6.4(8 I)$ & \\
\hline Exercise level & Sedentary & $29.3(244)$ & 0.77 & $3.8(31)$ & $<0.01$ \\
\hline & Low & $27.4(291)$ & & $7.6(81)$ & \\
\hline & Moderate & $28.8(2 \mid 3)$ & & $9.0(67)$ & \\
\hline & High & $26.8(63)$ & & $14.5(34)$ & \\
\hline High-risk alcohol use & No & $27.6(791)$ & 0.82 & $7.6(216)$ & 0.19 \\
\hline & Yes & $28.5(47)$ & & $4.8(8)$ & \\
\hline
\end{tabular}

Notes: "Pain/stiffness in at least one site including hand, foot, shoulder, back, hip, and knee; ${ }^{\dagger}$ self-reported doctor diagnosis; ${ }^{\ddagger}$ clinic determined

Abbreviations: BMI, body mass index; CES-D, Center for Epidemiologic Studies Depression Scale; CM, complementary medicine; COPD, chronic obstructive pulmonary disease; CVD, cardiovascular disease. 
Table 4 Oral complementary medicine and alternative practitioner use in relation to health service use in previous 12 months and patient factors

\begin{tabular}{|c|c|c|c|c|c|}
\hline Health service providers & & $\begin{array}{l}\text { Oral CM use } \\
\%(n)\end{array}$ & $P$ & $\begin{array}{l}\text { Alternative } \\
\text { practitioner } \\
\% \text { (n) }\end{array}$ & $P$ \\
\hline \multirow[t]{3}{*}{ Primary care provider visits previous year } & 0 & $11.6(3 \mathrm{I})$ & $<0.01$ & $9.5(26)$ & 0.30 \\
\hline & $1-4$ & $28.5(468)$ & & $7.2(120)$ & \\
\hline & $5+$ & $30.6(373)$ & & $6.8(84)$ & \\
\hline \multirow[t]{2}{*}{ Psychologist } & No & $27.6(846)$ & 0.055 & $7.2(224)$ & 0.74 \\
\hline & Yes & $41.0(25)$ & & $8.3(5)$ & \\
\hline \multirow[t]{2}{*}{ Chiropractor } & No & $26.4(706)$ & $<0.01$ & $5.9(159)$ & $<0.01$ \\
\hline & Yes & $36.1(163)$ & & $15.3(70)$ & \\
\hline \multirow[t]{2}{*}{ Alternative therapist } & No & $26.4(764)$ & $<0.01$ & & \\
\hline & Yes & $46.1(105)$ & & & \\
\hline \multicolumn{6}{|l|}{ Patient factors } \\
\hline \multirow[t]{3}{*}{ Risk aversion } & Risk-takers & $26.3(93)$ & 0.30 & II.7 (42) & $<0.01$ \\
\hline & Moderately averse & $30.4(422)$ & & $8.7(122)$ & \\
\hline & Highly averse & $28.9(164)$ & & $3.9(22)$ & \\
\hline \multirow[t]{4}{*}{ Patient satisfaction } & Very satisfied & $32.3(317)$ & 0.60 & $7.5(74)$ & 0.57 \\
\hline & Somewhat satisfied & $29.4(156)$ & & $9.4(5 \mathrm{I})$ & \\
\hline & Somewhat dissatisfied & $29.6(34)$ & & $9.6(11)$ & \\
\hline & Very dissatisfied & $35.7(15)$ & & $2.4(\mathrm{I})$ & \\
\hline \multirow[t]{3}{*}{ Decision-making preferences } & Patient decides & $30.1(286)$ & $<0.01$ & $9.2(88)$ & 0.37 \\
\hline & Shared decision & $33.3(230)$ & & $7.3(52)$ & \\
\hline & Doctor decides & $24.6(164)$ & & $7.0(47)$ & \\
\hline
\end{tabular}

Abbreviation: CM, complementary medicine.

Consistent with previous studies, we found that women and those with postsecondary education were more likely to use oral complementary medicines. ${ }^{2-4,26,27}$ However, unlike other studies, we found that oral complementary medicine use was increased in older people ( $>45$ years) compared with the younger age group, and numbers of complementary medicine used were associated with differing patterns of social and morbidity factors. This suggests that oral complementary medicine users are not homogeneous in terms of beliefs, motivations, and needs, and these differences need to be examined ${ }^{28}$ Awareness of psychosocial factors that influence complementary medicine use may help providers get a better understanding of the fit between the person and the intervention ${ }^{29}$ and adjust treatment accordingly. People taking one oral complementary medicine were more likely to have diagnosed arthritis or a mental health condition, and attend their general practitioner frequently. It is possible that older people are more likely to use oral complementary medicines than other types of unconventional therapies, such as massage or exercise therapies, but this requires further investigation. Previous US work has indicated that older age is positively associated with dietary supplements but negatively correlated with alternative practitioner use. ${ }^{30}$ This may also reflect general practitioners recommending certain oral complementary medicines to older people with chronic conditions where there is demonstrated or perceived efficacy, eg, fish oil or St John's wort. ${ }^{31}$ However, the main reason cited by participants for complementary medicine use was for general health and well-being, rather than for specific conditions. This seems to be in accordance with our findings that never or reformed smokers rather than current smokers were more likely to use oral complementary medicines, and that participants with a healthy body mass index were more likely to be complementary medicine users.

A strength of our study is the analysis of complementary medicine use in relation to patient factors in a representative sample, which has been rarely reported. We found a positive association of oral complementary medicine use with patient decision-making preferences, in contrast with studies reporting no association. ${ }^{8}{ }^{811}$ Consistent with previous findings, ${ }^{8}$ complementary medicine users are not rejecting the more conventional health care sector, because general practitioner visits were more frequent than among nonusers. Similarly, our findings indicate that oral complementary medicine use was not associated with dissatisfaction with health system experiences, consistent with previous reports in two representative samples from the US, ${ }^{8,10}$ or is unrelated to satisfaction with physicians. ${ }^{32}$

People who saw a complementary practitioner (naturopath or osteopath) were more likely to report taking multiple oral complementary medicines, and were significantly more likely to be risk-takers than oral complementary medicine users, who were no different from the nonuser population in this 
Table 5 Multivariable logistic regression analyses of factors associated with oral complementary medicine use overall and for patterns of oral complementary medicine use

\begin{tabular}{|c|c|c|c|}
\hline Factors & Any oral CM use & One oral CM versus none & $\geq$ Two oral CMs versus none \\
\hline Demographics & OR $(95 \% \mathrm{Cl})$ & OR $(95 \% \mathrm{Cl})$ & OR $(95 \% \mathrm{Cl})$ \\
\hline \multicolumn{4}{|l|}{ Sex } \\
\hline Male & 1.00 & 1.00 & 1.00 \\
\hline Female & $1.75(1.42-2.15)$ & $\mathrm{I} .83(\mathrm{I} .40-2.4 \mathrm{I})$ & $1.64(1.25-2.16)$ \\
\hline \multicolumn{4}{|l|}{ Age, yr } \\
\hline$<45$ & 1.00 & 1.00 & 1.00 \\
\hline $45-64$ & $1.98(\mid .55-2.5 I)$ & $1.91(1.41-2.60)$ & $2.04(I .49-2.8 I)$ \\
\hline $65+$ & $2.47(1.77-3.43)$ & $2.05(1.33-3.14)$ & $2.90(1.89-4.45)$ \\
\hline \multicolumn{4}{|l|}{ Education } \\
\hline Secondary & 1.00 & 1.00 & 1.00 \\
\hline Diploma, trade qualification & $1.33(1.07-1.67)$ & $1.53(1.15-2.05)$ & $1.15(0.85-1.54)$ \\
\hline University degree & $1.23(0.9 \mid-1.67)$ & $1.51(1.01-2.26)$ & $1.05(0.7|-| .56)$ \\
\hline \multicolumn{4}{|l|}{ Annual household income } \\
\hline$<\$ 20,000$ & 1.00 & 1.00 & 1.00 \\
\hline$\$ 20,00 \mathrm{I}-50,000$ & $1.53(1.15-2.05)$ & $1.29(0.90-1.85)$ & $2.00(1.34-2.98)$ \\
\hline$\$ 50,001-80,000$ & $1.78(1.27-2.49)$ & $1.44(0.95-2.18)$ & $2.33(1.46-3.70)$ \\
\hline$\geq \$ 80,00 \mathrm{I}$ & $1.64(1.14-2.37)$ & $1.20(0.75-1.92)$ & $2.30(1.39-3.77)$ \\
\hline \multicolumn{4}{|l|}{ Chronic disease } \\
\hline \multicolumn{4}{|l|}{ Diagnosed joint pain* } \\
\hline No & 1.00 & 1.00 & 1.00 \\
\hline Diagnosed arthritis (OA/RA) & I.4I (I.07-1.85) & $1.70(1.20-2.43)$ & $1.17(0.82-1.68)$ \\
\hline Undiagnosed joint pain & $1.26(1.01-1.59)$ & $1.26(0.94-1.7 I)$ & $1.29(0.95-1.74)$ \\
\hline \multicolumn{4}{|c|}{ Depressive symptoms CES-D } \\
\hline None & 1.00 & 1.00 & 1.00 \\
\hline Mild & $2.13(1.52-3.00)$ & $3.03(2.06-4.45)$ & $1.05(0.63-1.75)$ \\
\hline Moderate/Severe & $1.78(1.07-2.97)$ & $2.14(1.18-3.87)$ & $1.57(0.77-3.20)$ \\
\hline \multicolumn{4}{|l|}{ Risk factors } \\
\hline \multicolumn{4}{|l|}{ Smoking status } \\
\hline Current & 1.00 & 1.00 & 1.00 \\
\hline Never & $1.07(0.80-1.43)$ & $0.81(0.57-1.14)$ & $1.65(1.05-2.59)$ \\
\hline Former & $1.20(0.88-1.59)$ & $0.70(0.49-1.01)$ & $2.39(1.52-3.77)$ \\
\hline \multicolumn{4}{|l|}{ BMIt } \\
\hline Normal & $1.23(0.96-1.57)$ & $1.06(0.78-1.48)$ & $1.47(1.06-2.03)$ \\
\hline Overweight & $0.80(0.63-1.02)$ & $0.82(0.61-1.12)$ & $0.78(0.56-1.08)$ \\
\hline Obese & 1.00 & 1.00 & 1.00 \\
\hline \multicolumn{4}{|c|}{ Health service use in previous 12 months } \\
\hline \multicolumn{4}{|c|}{ Primary care provider } \\
\hline No visits & 1.00 & 1.00 & 1.00 \\
\hline $\mathrm{I}-4$ & $3.77(2.24-6.33)$ & $2.68(1.42-5.07)$ & $5.96(2.62-13.5)$ \\
\hline $5+$ & $3.62(2.13-6.17)$ & $2.41(1.25-4.63)$ & $6.21(2.70-14.3)$ \\
\hline \multicolumn{4}{|l|}{ Psychologist } \\
\hline No & 1.00 & 1.00 & 1.00 \\
\hline Yes & $2.89(1.5 \mid-5.53)$ & $1.53(0.64-3.66)$ & $4.27(2.00-9.13)$ \\
\hline \multicolumn{4}{|l|}{ Alternative practitioners ${ }^{\ddagger}$} \\
\hline No & 1.00 & 1.00 & 1.00 \\
\hline Yes & $2.62(1.87-3.66)$ & $1.38(0.85-2.23)$ & $4.59(3.11-6.78)$ \\
\hline \multicolumn{4}{|l|}{ Risk aversion } \\
\hline Risk-takers & $1.35(0.96-1.91)$ & $1.23(0.78-1.94)$ & $1.39(0.89-2.17)$ \\
\hline Moderately averse & $1.20(0.94-1.53)$ & $1.33(0.97-1.8 I)$ & $1.06(0.77-1.47)$ \\
\hline Highly averse & 1.00 & 1.00 & 1.00 \\
\hline \multicolumn{4}{|c|}{ Decision-making preferences } \\
\hline Patient decides & $1.38(1.08-1.77)$ & I.3I (0.96-I.79) & $1.54(1.11-2.15)$ \\
\hline Shared decision & $1.49(1.16-1.92)$ & $1.30(0.94-1.80)$ & $1.80(1.28-2.53)$ \\
\hline Doctor decides & 1.00 & 1.00 & 1.00 \\
\hline
\end{tabular}

Notes: ${ }^{*} P a i n /$ stiffness in at least one site including hand, foot, shoulder, hip, and knee; ${ }^{\dagger}$ clinic determined; ${ }^{*}$ includes visits to naturopath, osteopath.

Abbreviations: BMI, body mass index; CES-D, Center for Epidemiologic Studies Depression Scale; Cl, confidence interval; CM, complementary medicine; OA, osteoarthritis; $\mathrm{OR}$, odds ratio; RA, rheumatoid arthritis. 
Table 6 Complementary medicine used in people with self-reported mental health disorders and joint pain, and in those seeing an alternative health practitioner (naturopath or osteopath)

\begin{tabular}{|c|c|c|c|c|c|c|c|}
\hline \multirow[b]{2}{*}{ CM (n) } & \multicolumn{2}{|c|}{$\begin{array}{l}\text { Mental health } \\
\text { condition }\end{array}$} & \multicolumn{3}{|l|}{ Joint pain } & \multicolumn{2}{|c|}{ CM practitioner } \\
\hline & No (2639) & Yes (477) & No (1235) & $\begin{array}{l}\text { Diagnosed } \\
\text { arthritis (648) }\end{array}$ & $\begin{array}{l}\text { Joint pain with } \\
\text { no arthritis diagnosis (I24I) }\end{array}$ & No (2894) & Yes (228) \\
\hline \multicolumn{8}{|l|}{ Number CMs } \\
\hline $0(2247)$ & $73.2(1931)$ & $66.2(316)$ & $78.1(964)$ & $63.9(4 \mid 4)$ & $70.5(875)$ & $73.6(2129)$ & $53.7(123)$ \\
\hline $1-2(696)$ & $21.5(568)$ & $26.8(128)$ & $17.4(2 \mid 5)$ & $28.2(183)$ & $24.2(300)$ & $22.0(636)$ & $27.1(62)$ \\
\hline $3-4(142)$ & $4.4(I I 5)$ & $5.7(27)$ & $4.0(49)$ & $6.5(42)$ & $4.1(51)$ & $3.7(107)$ & $14.4(33)$ \\
\hline $5+(3 I)$ & $0.9(25)$ & $1.3(6)$ & $0.6(7)$ & $1.4(9)$ & $1.2(15)$ & $0.7(2 \mathrm{I})$ & $4.8(\mathrm{II})$ \\
\hline $\begin{array}{l}\text { All vitamins: Multi, B, C, E, } \\
\text { Coenzyme QI0 (590) }\end{array}$ & I8.2 (48I) & $22.8^{*}(109)$ & $16.7(206)$ & $18.4(119)$ & $21.4^{*}(266)$ & $17.6(508)$ & $36.0^{*}(82)$ \\
\hline Fish oil (205) & $6.3(167)$ & $7.9(38)$ & $4.7(58)$ & $13.3^{*}(86)$ & $4.9(6 \mathrm{I})$ & $6.2(180)$ & $11.0^{*}(25)$ \\
\hline Glucosamine/shark cartilage (I75) & $5.6(147)$ & $5.9(28)$ & $1.8(22)$ & $13.7^{*}(89)$ & $5.1^{*}(63)$ & $5.1(149)$ & II. $0^{*}(25)$ \\
\hline Herbal $^{\dagger}($ I39) & $4.4(117)$ & $4.6(22)$ & $3.7(46)$ & $4.9(32)$ & $5.1(63)$ & $3.8(110)$ & $13.2^{*}(30)$ \\
\hline Mineral: Mg, Zn (78) & $2.3(6 I)$ & $3.6(17)$ & $1.8(22)$ & $2.6(17)$ & $3.2(40)$ & $2.2(65)$ & $5.7^{*}(13)$ \\
\hline St. John's wort (12) & $0.2(6)$ & $1.3^{*}(6)$ & $0.5(6)$ & $0.3(2)$ & $0.3(4)$ & $0.4(\mathrm{II})$ & $0.4(1)$ \\
\hline Gingko biloba (50) & $1.6(42)$ & $1.7(8)$ & $1.2(15)$ & $2.3(15)$ & I.7 (2I) & $1.6(45)$ & $2.2(5)$ \\
\hline Evening primrose (47) & I.6 (42) & $1.0(5)$ & $1.6(20)$ & I.I (7) & $1.6(20)$ & $1.5(43)$ & $2.2(5)$ \\
\hline Black cohosh (18) & $0.4(10)$ & $1.7^{*}(8)$ & $0.3(4)$ & $0.9(6)$ & $0.7(9)$ & $0.5(14)$ & $2.2^{*}(5)$ \\
\hline Saw Palmetto (13) & $0.5(12)$ & $0.2(1)$ & $0.3(4)$ & $0.6(4)$ & $0.5(6)$ & $0.4(12)$ & $0.4(1)$ \\
\hline Probiotics (15) & $0.3(9)$ & $1.3^{*}(6)$ & $0.5(6)$ & $0.3(2)$ & $0.6(7)$ & $0.3(9)$ & $2.6^{*}(6)$ \\
\hline
\end{tabular}

Notes: ${ }^{*} P<0.05$ compared with those without the condition; 'garlic, celery, ginseng, echinacea, "herbal", belladonna. Abbreviation: CM, complementary medicine.

respect. Previous US survey data suggest that people who attend complementary practitioners perceive themselves as risk-taking, whereas those that only rely on self-administered complementary medicine treatment rate themselves as not being different from the general population. ${ }^{7}$ In a large US population study, risk attitude was as strong a predictor of visits to complementary medicine providers than the main sociodemographic predictors of female gender, higher education, or middle-age. ${ }^{7}$

Our study is limited by its measurement of current complementary medicine use, and we were unable to determine how long people had been using complementary medicines or whether complementary medicine usage had occurred in the recent past. We also do not know how frequently people were using complementary medicines. There was also a potential bias from survey nonresponse, although response rates in our sample were higher than for comparable biomedical population studies. The strength of this study is the large representative population sample with known probability of selection, measurements of other known chronic disease risk factors, and a low drop-out rate in follow-up, and that participants brought in all medications they were taking and that usage was clarified at the clinic visits.

Our data suggests the likelihood of a clear split in the approach to complementary medicines of primary care physicians and other clinicians and that of complementary practitioners. General practitioners may be more comfortable recommending a limited range of complementary medicines where some evidence supports their use (eg, fish oil) and where the safety profile is reasonably well known and understood. In contrast, other health providers seem more likely to suggest other types of complementary medicines where evidence of efficacy is less well established (eg, probiotics) or the safety of these products is more problematic (eg, black cohosh), ${ }^{33,34}$ to their patients who are risk-takers and favor decision-making autonomy. Previous work has suggested people use complementary medicine "when it is consistent with their world view and conventional care is not relieving their symptoms". ${ }^{32}$ The side effects of conventional medicines in chronic conditions, such as mental health conditions and arthritis, and the longevity of treatment, may be prompts for individuals to seek alternative treatments which are perceived as "natural" and therefore less harmful and with fewer side effects. This raises issues of how health care services and regulators should respond to the annual expenditure of $\$ 1.31$ billion dollars on complementary medicines in Australia ${ }^{35}$ that are taken mostly for "health and well-being". MacLennan et al have identified that many people incorrectly assume that the Australian Therapeutic Goods Administration audits the 
efficacy and safety of complementary medicines ${ }^{4}$ and that complementary medicines are safe. ${ }^{6}$ The case for more detailed consumer product information for complementary medicine is given more credence if one considers both the variability in health literacy across the population ${ }^{36}$ and the variability in complementary medicine products with similar names. The question of what constitutes "informed consent" under these circumstances needs greater clarification, in terms of risks and benefits by prescribers and also at the point of sale. This need to inform consumers would also apply to those complementary medicines where evidence indicates they are efficacious and appropriate, and should be considered as part of an evidence-based therapeutic regimen.

\section{Acknowledgment}

The research was funded by the Queen Elizabeth Hospital Research Foundation, the University of Adelaide, and South Australia Health.

\section{Disclosure}

The authors report no conflicts of interest in this work.

\section{References}

1. Xue CCL, Zhang AL, Lin V, et al. Complementary and alternative medicine use in Australia: A national population-based survey. J Altern Complement Med. 2007;13:643-650.

2. Barnes PM, Bloom B, Nahin RL. Complementary and alternative medicine use among adults and children: United States, 2007. Natl Health Stat Report. 2009:1-23.

3. McFarland B, Bigelow D, Zani B, et al. Complementary and alternative medicine use in Canada and the United States. Am J Public Health. 2002;92:1616-1618.

4. MacLennan AH, Myers SP, Taylor AW. The continuing use of complementary and alternative medicine in South Australia: Costs and beliefs in 2004. Med J Aust. 2006;184:27-31.

5. MacLennan AH, Wilson DH, Taylor AW. Prevalence and cost of alternative medicine in Australia. Lancet. 1996;347:569-573.

6. MacLennan AH, Wilson DH, Taylor AW. The escalating cost and prevalence of alternative medicine. Prev Med. 2002;35:166-173.

7. Sturm R. Patient risk-taking attitude and the use of complementary and alternative medical services. J Altern Complement Med. 2000;6: 445-448.

8. Astin JA. Why patients use alternative medicine: Results of a national study. JAMA. 1998;279:1548-1553.

9. Conboy L, Kaptchuk TJ, Eisenberg DM, et al. The relationship between social factors and attitudes toward conventional and CAM practitioners. Complement Ther Clin Pract. 2007;13:146-157.

10. Eisenberg DM, Kessler RC, van Rompay MI, et al. Perceptions about complementary therapies relative to conventional therapies among adults who use both: Results from a national survey. Ann Intern Med. 2001;135:344-351.

11. Boon H, Westlake K, Deber R, et al. Problem-solving and decisionmaking preferences: No difference between complementary and alternative medicine users and non-users. Complement Ther Med. 2005;13: 213-216.
12. Grant J, Chittleborough C, Taylor A, et al. The North West Adelaide Health Study: Detailed methods and baseline segmentation of a cohort for selected chronic diseases. Epidemiol Perspect Innov. 2006;3:4.

13. Taylor A, Wilson D, Wakefield M. Differences in health estimates using telephones and door-to-door survey methods - a hypothetical exercise. Aust N Z J Public Health. 1998;22:223-226.

14. Taylor AW, Dal Grande E, Gill TK, et al. Do people with risky behaviours participate in biomedical cohort studies? BMC Public Health. 2006;6:11.

15. Dales R, Spitzer W, Tousignant P, Schechter M, Suissa S. Clinical interpretation of airway response to a bronchodilator. Epidemiologic considerations. Am Rev Respir Dis. 1988;38:317-324.

16. Appleton S, Adams R, Wilson D, Taylor A, Ruffin R; on behalf of the North West Adelaide Cohort Health Study Team. Spirometric criteria for asthma: Adding further evidence to the debate. J Allergy Clin Immunol. 2005;116:976-982.

17. Global Initiative for Chronic Obstructive Lung Disease. Global strategy for the diagnosis, management, and prevention of chronic obstructive pulmonary disease. 2006. Available from: http://www. goldcopd.com/Guidelineitem.asp?11=2\&12=1\&intId=1816. Accessed Aug 17, 2010.

18. Radloff L. The CES-D scale: A self-report depression scale for research in the general population. Appl Psychol Meas. 1977;1:385-401.

19. Zich JM, Attkisson CC, Greenfield TK. Screening for depression in primary care clinics: The CES-D and the BDI. Int J Psychiatry Med. 1990;20:259-277.

20. Ensel W. Measuring depression: The CES-D scale. In: Lin N, Dean A, Ensel WM, editors. Social support, life events and depression. New York, NY: Academic Press; 1986.

21. World Health Organization. Obesity: Preventing and managing the global epidemic. Report of a WHO consultation on obesity. Geneva: World Health Organization; 1997.

22. Australian Bureau of Statistics. National Health Survey: Users guide, Chapter 5 - Health Risk Factors. Cat no 4363.0.55.001. Canberra, Australia: Australian Bureau of Statistics; 2003.

23. National Heart Foundation, Australian Institute of Health and Welfare. Risk factor prevalence study: Survey no 3. Canberra: National Heart Foundation: 1989.

24. National Patient Safety Foundation. Public opinion of patient safety issues: Research findings. Chicago, IL: National Patient Safety Foundation, 1997. Available at: http://www.npsf.org/download/1997survey. pdf. Accessed Aug 18, 2010.

25. Clark R. Australian Patient Safety Survey. Health Issues. 2001;69: 20-24.

26. Robinson A, Chesters J, Cooper S. People's choice: Complementary and alternative medicine modalities. Complement Health Pract Rev. 2007;12:99-119.

27. Schernhammer E, Haidinger G, Waldhör T, et al. Attitudes about the use of complementary and alternative medicine in cancer treatment. J Altern Complement Med. 2009;15:1115-1120.

28. Sirois FM, Gick ML. An investigation of the health beliefs and motivations of complementary medicine clients. Soc Sci Med. 2002;55: 1025-1037.

29. Honda K, Jacobson J. Use of complementary and alternative medicine among United States adults: The influences of personality, coping strategies, and social support. Prev Med. 2005;40:56-63.

30. Ness J, Cirillo DJ, Weir DR, Nisly NL, Wallace RB. Use of complementary medicine in older Americans: Results from the Health and Retirement Study. Gerontologist. 2005;45:516-524.

31. National Heart Foundation of Australia and the Cardiac Society of Australia and New Zealand. Reducing risk in heart disease 2007. Guidelines for preventing cardiovascular events in people with coronary heart disease (updated 2008). Available at: http://www. heartfoundation.org.au/SiteCollectionDocuments/A\%20RR\%20 RRIHD\%202008Update\%20Summary\%20pdf.pdf. Accessed Aug 18, 2010. 
32. Testerman JK, Morton KR, Mason RA, Ronan AM. Patient motivations for using complementary and alternative medicine. Complement Health Pract Rev. 2004;9:81-92.

33. Pierard S, Coche J-C, Lanthier P, et al. Severe hepatitis associated with the use of black cohosh: A report of two cases and an advice for caution. Eur J Gastroenterol Hepatol. 2009;21:941-945.

34. Adverse Drug Reactions Advisory Committee. Hepatotoxicity with black cohosh. Australian Adverse Drug Reactions Bulletin. 2006;25:6. Available from: http://www.tga.gov.au/adr/aadrb/aadr0604.htm. Accessed Aug 18, 2010.
35. Harvey K. Controlling complementary medicine claims. Australian Prescriber. 2008;31:142-143. Available at: http://www.australianpre scriber.com/upload/pdf/articles/983.pdf. Accessed Aug 18, 2010.

36. Adams R, Appleton S, Hill C, et al. Risks associated with low functional health literacy in an Australian population. Med J Aust. 2009;191:530-534.

\section{Publish your work in this journal}

Clinical Epidemiology is an international, peer-reviewed, open access journal focusing on disease and drug epidemiology, identification of risk factors and screening procedures to develop optimal preventative initiatives and programs. Specific topics include: diagnosis, prognosis, treatment, screening, prevention, risk factor modification, systematic

Submit your manuscript here: http://www.dovepress.com/clinical-epidemiology-journal

\section{Dovepress}

reviews, risk \& safety of medical interventions, epidemiology \& biostatical methods, evaluation of guidelines, translational medicine, health policies \& economic evaluations. The manuscript management system is completely online and includes a very quick and fair peer-review system, which is all easy to use. 